${ }^{r}$ Universidade de São Paulo, Departamento de Sociologia, Brasil

waizbort@usp.br

Leopoldo Waizbort'

\title{
SIMMEL HOJE: ENTREVISTA COM OLLI PYYHTINEN
}

\author{
Tradução de Markus Hediger
}

Olli Pyyhtinen é professor de sociologia na Universidade de Tampere, na Finlândia, uma cidade que, pelo que me informa o Google, fica a cerca de I8o $\mathrm{km}$ ao Norte de Helsinki. Olli é o autor de um dos mais instigantes livros sobre Simmel escritos no século XXI, Simmel and "the social", publicado em 20Io. O conhecimento do livro, e o estranho do nome, levaram-me a propor uma entrevista; ao prepará-la, deparei-me com um novo livro seu, The gift and its paradoxes, no qual, é claro, Simmel também marca presença. A leitura dos dois livros despertou minha curiosidade pelo que se faz na sociologia finlandesa, até então muito distante de meu enraizamento tropical. Como quer que seja, olli Pyyhtinen é um dos representantes mais expressivos do debate sobre Simmel travado por sociólogos "de uma nova geração", digamos aquela que já pode começar e terminar de ler Simmel na edição das obras completas, algo impossível para a geração anterior, como a do entrevistador. As dez perguntas da entrevista, que foi feita como um vaivém por e-mail nos últimos meses de 20I4, dão uma ideia das preocupações e enfoques de Olli, abrindo o apetite para a leitura de seus livros e para acompanhar as suas pesquisas ainda em andamento.

Seguem-se à entrevista os artigos de Donald Levine e Otthein Rammstedt, dois dos mais importantes investigadores do pensamento de Simmel da geração mais velha, um alemão e um norte-americano nascidos nos anos I930. Rammstedt doutorou-se com Gottfried Salomon-Delatour, um dos pou- 
cos doutorandos de Simmel em Estrasburgo, e responsabilizou-se, durante os últimos 30 anos, pela edição das obras completas de Simmel; Levine é uma cria de Chicago, desde sempre um centro de interesse e de irradiação do pensamento de Simmel fora da Alemanha. É impossível pensar Simmel hoje sem o trabalho de Rammstedt, que disponibilizou, pela primeira vez, o conjunto dos escritos de Simmel em uma edição que, iniciada nos anos I980, acaba de ser concluída. E, no âmbito norte-americano, é impossível pensar em Simmel sem lembrar da coletânea editada por Levine, assim como seus numerosos artigos sobre Simmel.Ambos oferecem uma imagem diversificada dos caminhos percorridos pelo pensamento de Simmel.

Soma-se a eles o artigo de Lenin Barbara, autor que, como Olli Pyyhtinen, representa a geração que acaba de chegar aos estudos simmelianos. É a primeira geração que já encontra um Simmel prontinho para ler, editado e na prateleira, à diferença da geração anterior, intermediária (à qual pertenço), que ainda precisava buscar, com dificuldade, textos em periódicos de difícil acesso, ficar em dúvida com relação à autoria de alguns textos anônimos ou publicados sob pseudônimo, ou buscar edições dos anos 1900, I910 e I920, nunca mais reimpressas. A nova geração trabalha sobre uma plataforma forjada pela geração de Levine e Rammstedt e bastante alargada e aprofundada pela geração intermediária, dado o boom que o interesse por Simmel sofreu desde o final da década de I970, propiciando, por todos os cantos, a publicação de artigos, livros e traduções. À diferença de Levine e Rammstedt, a jovem geração é representada por autores diferentemente "periféricos", a evidenciar com clareza o nível de sofisticação que a pesquisa sobre Simmel atingiu por toda parte. E, importante lembrar, esse conjunto se complementa e completa com o importantíssimo texto de Simmel "Excurso sobre o problema: como é possível a sociedade?", publicado em Sociologia \& Antropologia, vol. 3, n. 6, 2013, p. 653-672.

Com a aproximação do centenário de morte de Georg Simmel (I858I9I8), oxalá, juntando essa gente em uma espécie de conversa intergeracional, se possa estimular mais e mais a leitura e a reflexão de Simmel e com Simmel, um daqueles autores com quem sempre se pode aprender um bocadinho mais.

Leopoldo Waizport. Olli, você é sociólogo de um lugar bastante desconhecido do ponto de vista brasileiro. A Finlândia não só é distante, mas é também desconhecida do público brasileiro no que diz respeito às ciências sociais. Você poderia nos contar um pouco sobre Simmel na Finlândia? Como e por que você decidiu escrever um livro sobre ele?

olli Pyyhtinen. As duas grandes tradições, por assim dizer, da sociologia finlandesa têm sido a tradição de Westermarck, de um lado e, de outro, a tradição que usa a sociologia norte-americana da década de I950 como seu modelo e que se concentra no estudo de estruturas sociais por meio de mé- 
todos quantitativos. O antropólogo e etnólogo Edward Westermarck, do qual a associação sociológica nacional, a Westermarck Society, recebeu seu nome, costuma ser visto como o pai da sociologia finlandesa. Ele foi chamado para ser docente em sociologia na Universidade de Helsinki em I890, e mais tarde ocupou também uma cátedra na London School of Economics. Em sua obra, ele se ocupou especialmente com a história e o desenvolvimento da moral, com a história do casamento e também com os costumes e sua relação com a ordem social normativa. A chamada sociologia moderna, porém, chegou à Finlândia relativamente tarde, apenas após a Segunda Guerra Mundial. Até então, a pesquisa sociológica realizada e o ensinamento oferecido nas universidades diziam respeito, sobretudo, à antropologia social e à etnologia. A nova sociologia moderna foi importada principalmente dos Estados Unidos, tendo autores como Robert Merton e Talcott Parsons como autoridades centrais. Não surpreende, portanto, que Simmel nunca tenha exercido uma influência maior sobre a sociologia finlandesa. Teria sido extremamente difícil encaixar sua obra em qualquer uma dessas duas grandes tradições.

Pelo que sei, o primeiro artigo sobre Simmel em finlandês foi publicado em I973 na revista finlandesa de sociologia Sosiologia. O artigo discutia sua metafísica da cultura. Foi, porém, apenas na década seguinte, creio eu, que os sociólogos da Finlândia se tornaram mais familiarizados com Simmel, por meio da chamada virada cultural e também em virtude do interesse crescente pelos temas da modernidade e pós-modernidade. Na década de I980, alguns textos seus foram traduzidos, um ensaio sobre a ruína e o outro sobre a moda. No final da década de I990, mais dois vieram à luz: uma tradução parcial de Philosophie des Geldes [Filosofia do dinheiro] e uma tradução de Grundfragen der Soziologie [Questões fundamentais da sociologia], inclusive uma tradução do primeiro capítulo de Soziologie [Sociologia. Investigações sobre as formas de socialização]. Na primeira década de 2000 foi publicada uma coleção de ensaios traduzidos de Simmel sobre a modernidade e a vida moderna. Além disso, eu mesmo traduzi alguns ensaios e organizei um dossiê sobre Simmel para uma revista filosófica. Nos trinta anos que se passaram desde a publicação das primeiras traduções, o interesse pela obra de Simmel tem crescido na Finlândia. Ele já tem alguns fãs, e as pessoas têm recorrido às suas ideias em discussões sobre assuntos relacionados à economia, ao urbanismo, ao turismo, ao gosto, à moda e à família, por exemplo. No entanto, poucos estudiosos têm realizado pesquisas sobre Simmel. Até hoje, existe uma única monografia sobre Simmel escrita em finlandês, de Arto Noro, publicada em I99I. Além de mim, porém, existem alguns outros que escreveram sobre Simmel em inglês. Vêm-me à mente, além do meu livro Simmel and "the social" (2010), principalmente The sociology of taste (1997), de Jukka Gronow, e Reason of sociology: Georg Simmel and beyond (2010), de Kauko Pietilä. 
O que me atraiu inicialmente em Simmel foi, acima de tudo, o seu programa sociológico de estudar, como ele mesmo diz, o que, na sociedade, é realmente "sociedade". Ele aborda a sociedade e o social como problemas, como algo que exige explanação em vez de explicação. Minha própria abordagem de Simmel é marcada pelo esforço de pensar com ele. Estou menos interessado em buscar comentários reverenciais e mais em tornar seus conceitos e suas ideias relevantes para os debates e as discussões contemporâneas. Sinto que sua obra pode contribuir muito para os assuntos e temas atuais e que grande parte de seu vasto potencial ainda aguarda atualização. Esta é razão pela qual eu quis escrever o livro.

L.W. Antes de prosseguirmos, permita-me mais uma pergunta sobre a sociologia na Finlândia. A Escola de Chicago e o estudo da cidade nunca estiveram presentes? (Pergunto isto, porque, no Brasil e também em outros lugares, a Escola de Chicago serviu como veículo importante para introduzir um Simmel específico na pesquisa e discussão sociológica e também nos departamentos de sociologia.) Simmel está presente nos currículos? Desde quando? Quando você estudava, Simmel fazia parte das leituras obrigatórias? E agora? O.P. Sem dúvida alguma, a Escola de Chicago tem exercido - e ainda exerce em certa medida - uma influência na Finlândia, sobretudo no campo da sociologia urbana, mas não foram os escritos da Escola de Chicago que trouxeram Simmel para a sociologia finlandesa. O artigo publicado em I973 havia sido escrito por um estudioso marxista, Seppo Toiviainen, que discutiu Simmel também em seu livro sobre o jovem Georg Lukács [Nuori Lukács, Helsinki: Kansankulttuuri], publicado em I977. Na verdade, é um tanto paradoxal o fato de ter sido um estudioso marxista quem basicamente apresentou Simmel ao público de sociologia na Finlândia, visto que, em I970, o interesse na sociologia clássica, que já era baixo na época, se tornou quase inexistente em decorrência da ênfase marxista.

$\mathrm{Na}$ época dos meus próprios estudos de sociologia, mais ou menos por volta da virada do milênio, Simmel já havia se tornado uma parte mais ou menos evidente do currículo, ensinado especialmente em módulos como Teoria Sociológica e História da Sociologia. E ele continua a ser, com exceção da universidade de Tampere, onde comecei a trabalhar como professor em agosto deste ano. Mas terei que fazer algo a respeito disso logo!

L.W. Gostei de sua formulação "pensar com ele" (Simmel), pois Simmel sempre parece nos convidar para acompanhá-lo. Anos atrás, fiquei impressionado com as descrições de seus estudantes, publicadas em Buch des Dankes an Georg Simmel [Livro de agradecimento a Georg Simmel]: quase todos experimentaram algo parecido com esse "convite" em suas aulas, conferências, palestras, e com uma intensidade incomum. Para nós, os "Nachgeborene" [os 
nascidos posteriormente], os textos são a única fonte, mas o apelo é muito presente... Conte-nos um pouco sobre sua experiência de leitura, como ela o capturou.

O.P.: É verdade. Como você mencionou, muitos dos contemporâneos de Simmel se sentiam atraídos por seu pensamento. Ele era uma figura proeminente da inteligência berlinense, seus livros eram lidos por muitos e suas palestras eram eventos significativos, anunciados até em jornais. Ao mesmo tempo, porém, apesar de alguns aceitarem seu convite, de certa forma sua dádiva não teve retorno, não foi respondida por uma contra-dádiva. A história intelectual não conhece simmelianos. Aparentemente, as pessoas extraíram apenas o que melhor servia a seus propósitos e seguiram seus próprios caminhos - como o próprio Simmel havia predito quando comparou seu legado intelectual com dinheiro. O dinheiro tem uma grande circulação, mas sua origem permanece muitas vezes desconhecida para aqueles que o usam.

Minha própria experiência de ler Simmel certamente lembra aquilo que você acaba de descrever. O pensamento e os escritos de Simmel me agradam e me inspiram como as obras de pouquíssimos outros autores. Além de achar que sua obra é uma fonte incrivelmente rica de informação e inspiração, seu estilo de pensar e seu gosto por conceitos e problemas me atraem igualmente. Para mim, existe uma forte dimensão afetiva e estética em seus textos. Assim, eu diria que tanto o conteúdo quanto a forma dos textos de Simmel me atraem (o que é, naturalmente, uma maneira muito simmeliana de me expressar, dada a centralidade das noções de "conteúdo" e "forma" em sua obra...).

L.W. Vamos então falar do seu livro Simmel and "the social", publicado em 2010. Ele tem o grande mérito de deixar claro o núcleo, por assim dizer, da concepção do social de Simmel: relações e processos. É muito surpreendente que esse núcleo de seu pensamento tenha sido negligenciado ou pelo menos não ressaltado suficientemente por tanto tempo.

a) O que ele realmente quer dizer quando fala de relações e processos?

b) Quais são os fundamentos para essa concepção de relações e processos?

c) Como ele construiu sua concepção do social a partir desta perspectiva?

d) Existem precursores neste modo de pensar que foram relevantes para ele? Em caso afirmativo, como Simmel reelaborou essas contribuições anteriores?

O.P. Deixe-me começar com uma observação sobre a dificuldade de descobrir o que Simmel quis dizer com qualquer coisa, visto que seus conceitos nem sempre costumam permitir uma interpretação inequívoca. (De um modo bem geral, creio que seja impossível reconstruirmos o que um autor "realmente" quer dizer.) Além do fato de que os significados de seus conceitos podem variar e mudar em contextos diferentes, ele tende também a usar várias pa- 
lavras para designar aproximadamente a mesma coisa. Seja como for, no que diz respeito às relações, a obra de Simmel é profundamente relacional. Ele defende um tipo de epistemologia relacional, pois considera a verdade uma relação entre proposições; ele desenvolve uma ontologia relacional que percebe o real em termos de relações; e sua sociologia também é relacional, pois considera a sociedade e o social em termos de uma interatividade contínua dos indivíduos. Não importa sobre o que Simmel escreva, ele nunca trata seus objetos como substâncias monolíticas ou isoladas, mas sempre os dissolve em relações. E ele parece operar com basicamente dois tipos de relações em sua obra. As relações de analogia representam o primeiro tipo. Os escritos de Simmel estão repletos de analogias: ele compara o dinheiro, por exemplo, com Deus, no sentido em que o dinheiro tem se tornado o denominador comum das coisas mais opostas e distantes, ele reconhece uma analogia entre a sociabilidade, a arte e o jogo, e sugere que limites são para as relações sociais o que a moldura é para uma obra de arte. Simmel até previu o destino de sua própria obra criando uma analogia com o dinheiro, como já mencionei acima. O segundo tipo de relações revela algo muito além de meras analogias: estas relações dizem respeito a como as coisas fazem parte umas das outras, ou seja, como elas são conectadas ou vinculadas na realidade, apesar de sua aparente desconexão. Estas relações, portanto, pertencem à realidade e à constituição das coisas. Para Simmel, não existe nada absoluto que existiria em si e por si só, pois as coisas consistem de relações.

$\mathrm{Na}$ visão de Simmel, as relações são essencialmente recíprocas. Para ele, nenhuma relação é como uma flecha lançada em uma única direção, simples e irreversível; todas as relações envolvem reciprocidade, ou Wechselwirkung, literalmente "interação recíproca". Sua compreensão das relações é, portanto, processual e dinâmica: em vez de compreender "relação" como uma "coisa" mais ou menos fixa (como, por exemplo, uma corda ou um fio) que amarra as pessoas umas às outras, ele a vê como processo contínuo, como jogo cambiante de forças. A preocupação de Simmel com processos se manifesta já em sua tese de doutorado, "Das Wesen der Materie nach Kants Physischer Monadologie" [A essência da matéria na monadologia física de Kant], publicada em I88I. Nela, ele critica Kant por tratar a matéria como realidade hipostática separada das forças que a produzem. Contrariando Kant, Simmel defende uma compreensão "realista-dinâmica" da matéria. Segundo ele, a matéria deveria ser concebida como "processo molecular"; trata-se de um modo de devir, não de ser. Sua concepção posterior da sociedade apresenta uma semelhança surpreendente com esta visão. Ele vê a sociedade em termos de reciprocidade viva, como processo de associação que se dobra, desdobra e volta a se dobrar constantemente.

A noção da Wechselwirkung [interação, interação recíproca] aparece já em Kant, Hegel, Schleiermacher e Dilthey, mas Simmel é o primeiro a aplicá- 
-la à sociologia e a atualizar seu rico potencial para a sociologia. Em sua obra, as relações de Wechselwirkung ocupam o centro da sociologia.

Consequentemente, a grande contribuição de Simmel é, a meu ver, que ele liberta a análise sociológica dos modos reificantes de pensar e falar. Em vez de partir de indivíduos e de suas ações ou de sociedades e de suas estruturas, ele parte das relações dinâmicas e cambiantes da Wechselwirkung. Para ele, o mundo social não consiste de entidades num estado de descanso e encerradas em si mesmas, mas do fluxo e da pulsação que conecta os indivíduos uns aos outros. Consequentemente, ele insiste que a reciprocidade de efeitos deveria ser o ponto de partida para o estudo de todas as formações sociais. Num livro que estou escrevendo atualmente, tento desdobrar essa virada relacional que a obra de Simmel incentiva na sociologia, pois o tratamento que conferi ao tema em Simmel and "the social" me deixou um tanto insatisfeito, para dizer a verdade. A noção da "relação" em si, por exemplo, merece uma análise mais profunda e detalhada. E isso é precisamente algo que será discutido no livro mencionado, entre outras coisas.

L.W. Existe um limite (ou uma margem) para este tipo de pensamento relacionista? Seria o mundo inteiro, ou cosmo, uma relação? Não existe nada substancial anterior (em termos lógicos) às relações? Seriam as relações aquilo que faz o mundo? Somos confrontados com uma concepção de energia, de ergon, por trás (ou na base) deste relacionismo? E mais: se relações "produzem" ou "resultam" em algo ("o social", por exemplo), estamos falando de poiesis?

O.P. Apesar de defender o relacionalismo, não penso que não exista nada além de relações. Portanto, sim, neste sentido há definitivamente um limite para o caráter relacional e para o pensamento relacional. Relações não esgotam todo o real. E creio que Simmel também concordaria com isto. Ao mesmo tempo em que Simmel insiste que nós somos determinados até a nossa essência pelo fato de existirmos em conjunto com outras pessoas, ele destaca também que cada indivíduo não é apenas parte da sociedade, mas também algo além disto. Além do mais, e isto é importante, ele sugere que é isto que, parcialmente, possibilita as nossas relações. Uma precondição da vida social é que a vida não é completamente social.

Portanto, quando alguém se recusa às relações, ele não vê isto apenas de forma negativa, como mera ausência ou negação de relações, mas também de forma positiva, como algo que pertence fundamentalmente ao ser e à constituição de relações. A impossibilidade de reduzir a vida a relações é, evidentemente, o que está basicamente em jogo, embora expresso em termos um pouco diferentes, na preocupação com a biopolítica, por exemplo. Ao mesmo tempo em que as técnicas biopolíticas tentam controlar e administrar a vida, esta também se esquiva constantemente a quaisquer tentativas de dominá-la. 
Uma das razões pelas quais a filosofia da vida de Simmel importa é, como tenho argumentado em meu trabalho, que ela examina em que aspectos a vida não pode ser reduzida à área social e, assim, nunca pode se emaranhar nas redes de poder/conhecimento. Para Simmel, a vida, ao mesmo tempo em que se manifesta e subsiste apenas em alguma forma, não pode ser confinada a uma forma, como em um organismo, em um indivíduo humano ou em uma sociedade. Para ele, a vida é o emblema de movimento, um decurso do devir; ela está sempre se tornando algo diferente a cada momento.

Onde minha própria visão, porém, diverge daquela de Simmel é que eu, diferentemente dele, não deduzo que a impossibilidade de reduzir as coisas às relações "ocultaria" as entidades. Heidegger levou o jogo recíproco de esconder-revelar ou ocultar-presenciar bem além de Simmel e o transformou em tema explícito, mas a concepção de Simmel do indivíduo também se caracteriza por algo assim. Ele acredita que o indivíduo permanece, em última instância, inatingível e um segredo para os outros - e, em certo sentido, até para si mesmo. Enquanto isto, sugere uma divisão dentro de cada indivíduo entre um núcleo interior e uma aparência, ou seja, entre aquilo que eu sou e aquilo que os outros veem em mim, eu argumentaria em prol de uma visão mais radical: o que você percebe na experiência são, paradoxalmente, as coisas-em-si. Preciso confessar que, neste ponto, eu sou um seguidor de Whitehead, que ressaltou que não há nada fora da experiência: "além da experiência dos sujeitos não há nada, nada, nada, simplesmente nada", como ele diz em Process and reality (I929). Portanto, não há nada "oculto" na coisa, apenas algo desconhecido ou, alternativamente, algo que tem sido "abstraído", excluído da imagem. Em certa medida, todas as relações abstraem as entidades às quais elas se conectam, no sentido de não abarcarem todas as suas propriedades. Por exemplo: quando estou diante de uma turma de alunos, estou ali como professor e sociólogo, não como pai, marido, filho, amigo, amante de música, fã de esportes ou bibliófilo, coisas que posso ser em outras circunstâncias e em relação a outras pessoas. Mas a questão não se limita a papéis, tampouco a relações humanas. Por exemplo, a vela de um barco "abstrai" o vento, no sentido em que aproveita sua força independentemente de como ele cheira, de sua temperatura ou umidade. E enquanto escrevo isto, eu abstraio alguns recursos do processador de textos no meu laptop, pois uso apenas uma parte pequena de suas mais ou menos I.500 funcionalidades.

Isto nos leva à produtividade das relações. Em termos lógicos, é verdade que duas coisas podem estar conectadas por meio de uma relação apenas se essas coisas forem, de alguma forma, preexistentes à relação entre elas, mas nenhuma entidade é uma substância absoluta, final e autossuficiente. Eis um ensinamento importante de Simmel, mesmo que, até agora, este ponto não tenha sido devidamente reconhecido. Em sua sociologia, o 
indivíduo aparece muitas vezes como a menor unidade de análise, mas ele não vê os indivíduos como elementos últimos invisíveis e atômicos; antes, defende que os indivíduos são compósitos ou confederações. Para ele, a individualidade é produzida e preservada por meio de um conjunto de relações que todo indivíduo possui. O indivíduo é, portanto, apenas um "dado" arbitrário do estudo; o processo de dissolver entidades em suas relações poderia, a princípio, ser continuado ad infinitum. Ele depende dos problemas que analisamos, dos compósitos que escolhemos como se fossem os elementos mais elementares que existem. No entanto, não é apenas sua constituição interna que é relacional (no sentido de serem compósitos de partes ou elementos inter-relacionados que, por sua vez, também são compósitos ou agrupamentos, e assim por diante), mas as entidades se constituem igualmente em relação ao seu exterior. Elas não existem exclusivamente por si mesmas e independentes de todo o resto, mas em relação aos seus ambientes e a outras coisas. Veja, por exemplo, o corpo humano vivo. Sem dúvida alguma, somos entidades materiais confinadas, separadas do nosso ambiente por nossa pele. A pele tem também a função vital de proteger o corpo de intrusos potencialmente perigosos. No entanto, não conseguimos sobreviver por nós mesmos, separados do nosso ambiente. Para sobrevivermos, precisamos constantemente ingerir e expelir materiais. Nas palavras do antropólogo Tim Ingold: somos capazes de existir apenas se e enquanto "vazarmos". Os corpos humanos vivos não são, portanto, substâncias autocontidas, mas configurações de fluxos, relações e materiais diferentes, desde processos bioquímicos até oxigênio, tecido nervoso, comida, água, substâncias químicas, bactérias etc. É também importante entender que não somos primeiro "alguém" [some-body; literalmente "algum corpo"] e apenas então nos relacionamos com nosso ambiente. Nosso corpo é produzido em e por meio dessas relações. Adquirimos e somos um corpo apenas por meio desses agrupamentos de materiais diferentes.

A despeito do fato de relações apresentarem um lado externo, as relações mesmo assim constituem as coisas. Mesmo que as relações atuais não esgotem uma entidade, é verdade também que nunca encontramos algo fora de circunstâncias específicas. As entidades existem e persistem apenas em determinados ambientes e circunstâncias, em relação a outras coisas. E a identidade das coisas depende de suas relações; as coisas só são capazes de permanecer as mesmas se e enquanto suas relações perdurarem e permanecerem as mesmas. A meu ver, uma das contribuições significativas dos estudos de ciência e tecnologia (Science and Technology Studies [STS]) é a ideia da "instituição" [enactment]. Entidades são instituídas em e por meio de relações e práticas, ou seja, elas vêm a ser e desaparecem juntamente com as práticas que as produzem. Num projeto que estou iniciando no momento, eu e meus colegas estudamos o lixo; e creio que o lixo seja um bom exemplo aqui. Coisas como comida se transformam em lixo não necessariamente em 
decorrência de alguma mudança física nos materiais em si ou porque já passaram da data de vencimento; antes, transformam-se em lixo por meio de determinadas práticas como, por exemplo, quando são jogadas fora. Tendemos a considerar comida jogada no lixo como algo sujo, nojento e não comestível. Assim, o ato de jogar algo fora confere aos alimentos uma nova identidade ontológica. Seu status, porém, pode, evidentemente, permanecer indeterminado e complexo. Para moradores de rua, por exemplo, que reviram e resgatam o lixo de outras pessoas, ele podem ter algum valor. Eles atualizam um potencial ignorado por outros. Quando tiram a comida do lixo, limpam-na e cozinham-na, eles transformam lixo em alimento. Estamos, portanto, falando aqui não só de conferir uma nova interpretação ou um novo sentido ao mesmo objeto, mas das práticas que instituem um novo objeto com um novo conjunto de relações em comparação ao lixo descartado como inútil e imprestável. Talvez pudéssemos falar dessa instituição também em termos de "poiesis", levando em consideração que o termo se refere à criação e invenção.

Não acredito, portanto, que as entidades possuam uma essência autônoma preexistente às suas relações com outras entidades. Elas se transformam sempre que abandonam alguma relação ou estabelecem uma nova. É claro que, às vezes, estas transformações ou "devires" podem ser tão delicados que dificilmente podem ser observados. No entanto, as entidades e seus materiais sofrem transformações a cada momento. Elas só aparentam ser fixas e iguais. A palavra não é estática, mas um processo de devir. E esta é uma das coisas importantes que Simmel nos ensina.

L.W. Sua explicação é muito esclarecedora. Você acha que Simmel teve dificuldades de expressar o que realmente pensava? A linguagem é flexível ou dinâmica o suficiente para expressar seu modo de pensar? Você acredita que o uso de analogias é uma tentativa de contornar isto para expressar algo que a linguagem "normal" não consegue dizer?

O.P. Ainda que Simmel tenha reconhecido o abismo entre linguagem e mundo, como se vê, por exemplo, quando insiste no fato de que palavras não apresentam a mesma estrutura das coisas, não creio que Simmel tenha tido grandes dificuldades de se expressar por meio de palavras. Ao contrário: sendo um mestre da escrita ensaística (qualidade pela qual até mesmo Adorno, que era bastante crítico com relação a Simmel, o elogiou), eu diria que Simmel dominava as palavras muito bem, sobretudo se o compararmos com outros sociólogos clássicos, sem falar dos estudiosos medianos. De vez em quando, ele consegue expressar em uma oração ideias tão intensas que precisaríamos de um artigo ou de um livro para desdobrá-las - e mesmo assim, elas não são incompreensíveis, mas muito compreensíveis. Em geral, Simmel é, pelo menos para mim, uma leitura muito mais prazerosa do que, por exemplo, Weber! Os textos de Simmel apresentam uma qualidade estética que 
falta aos textos de Weber. E, como sabemos, Simmel publicou também alguns poemas, aforismos, contos de fadas e pequenas histórias na revista Jugend.

Agora, mesmo que seu domínio da língua alemã fosse bastante impressionante e prazeroso, eu diria que Simmel também sabia como a rigidez da linguagem restringe potencialmente o processo do pensamento e, por isso, tentou escrever de formas que vitalizariam a linguagem, ou seja, que lhe confeririam uma maior fluidez e flexibilidade. (Ao mesmo tempo, porém, Simmel certamente não era um filósofo da linguagem. E em suas análises sociológicas, a pergunta de como a linguagem intermedeia nossos relacionamentos permanece pouco teorizada, quase ignorada.) $O$ fato de ele ter preferido a noção mais processual e dinâmica da "associação" ou "socialização" (Vergesellschaftung), em vez do termo mais concreto e estático de "sociedade", é um exemplo. Outro exemplo é sua recusa em definir o conceito de "vida" em termos precisos. A seu ver, conferir um sentido exato a esta noção significaria negar a essência da vida como devir e movimento. No final das contas, Simmel parecia estar ciente da qualidade aberta dos conceitos - muitos dos nossos conceitos são do tipo que não conseguimos definir de modo totalmente inequívoco; eles não são delimitados sob todos os aspectos e são fadados a permanecer mais ou menos abertos em alguns deles. Disto resulta que as concepções permanecem em fluxo em e entre seus textos; elas se revelam como algo levemente diferente em contextos diferentes.

E as analogias, é claro, transferem significado de um termo para o outro. Mesmo assim, a meu ver, o uso de analogias em Simmel se refere menos aos limites da linguagem do que representa um meio de conhecimento e talvez até mesmo algo como sua metodologia. Eu diria que ele recorre a analogias com propósitos heurísticos. Ao conectar duas coisas e apresentá-las lado a lado, ele é capaz de produzir conhecimento novo. Por meio da analogia conseguimos compreender o desconhecido em termos conhecidos. As analogias nos permitem, assim, conceituar e compreender melhor o que não conhecemos relacionando-o àquilo que já conhecemos. Quando estabelecemos uma analogia entre dois fenômenos, destacamos sua semelhança. Ela chama a atenção para aquilo que eles têm em comum. Apresentar uma analogia não significa, evidentemente, dizer que exista uma equivalência (isto é, uma homologia) perfeita entre os termos relacionados, mas a comparação chama a atenção para a semelhança entre coisas, reconhecendo e preservando, ao mesmo tempo, suas diferenças. Neste sentido, poderíamos talvez dizer que analogias tratam de reconhecer semelhanças em diferenças. É, também, interessante observar que Simmel tende a usar analogias não só para tornar palpável algo novo e menos familiar comparando-o com o mais familiar, mas tenta também descobrir algo novo em ambos os fenômenos. Ao comparar a sociabilidade com o jogo, por exemplo, ele lança uma nova luz não só sobre a sociabilidade, mas também sobre o jogo. Graças à relação de 
analogia que se estabelece, somos capazes de ver ambos os termos relacionados sob uma nova perspectiva e sob uma nova luz. O uso da analogia poderia, então, ser visto como maneira de rejeitar o essencialismo e de introduzir o perspectivismo.

L.W. Em sua opinião, quais são os maiores desafios do pensamento de Simmel para o nosso tempo atual?

O.P. Interpreto este desafio que você mencionou em dois sentidos. O primeiro tem a ver com o desafio da recepção de sua obra. Simmel nos é, ao mesmo tempo, próximo e distante, como Habermas o expressou em seu prefácio a uma edição de Philosophische Kultur [Cultura filosófica]. E a distância, o fato de ele não ser um contemporâneo nosso, torna difícil compreendermos completamente as suas ideias. O mundo em que seus textos vieram à luz e em que desdobraram seus efeitos não é nosso mundo atual, é um mundo passado; as discussões e os debates para os quais eles contribuíram não nos são completamente acessíveis; e as questões com que eles se preocupavam não são necessariamente as nossas. O que torna a recepção da sociologia de Simmel especialmente desafiadora diante da grande tradição é sua peculiaridade. Sua escolha incomum de temas e seu modo pouco ortodoxo de pensar dificulta seu posicionamento em relação à tradição clássica. Em vez de examinar as mesmas questões como os outros clássicos, Simmel transformou toda a paisagem dos problemas sociológicos. E creio que correríamos o risco de perder algo da originalidade de sua obra se tentássemos inseri-la na corrente principal da sociologia e tentássemos entendê-la (apenas) em termos dos problemas sociológicos padronizados.

O segundo sentido em que entendo o desafio da obra de Simmel está relacionado a isto. Ao reestruturarem a paisagem da pesquisa sociológica, os escritos de Simmel nos desafiam a pensar de forma diferente. Quando levada a sério, sua obra nos oferece novas possibilidades de pensar, talvez até de agir e ser. Uma "nova ideia introduz uma nova alternativa", como Whitehead costumava dizer.

A meu ver, a obra de Simmel altera a paisagem dos problemas sociológicos e reestrutura a imaginação sociológica de três maneiras - e isto representa o núcleo do meu argumento referente ao legado de Simmel no livro The Simmelian legacy, que estou escrevendo no momento. Durante a nossa conversa já me referi a alguns destes pontos. Em primeiro lugar, em vez de explicar fenômenos concretos por meio de categorias e princípios abstratos, a obra de Simmel é explanatória das abstrações. É bastante comum que sociólogos tratem "sociedade", "normas", "poder" e "capitalismo", por exemplo, como fatores explanatórios. A abordagem de Simmel, porém, é bem diferente. Em vez de vê-los como causas que já estão dadas, Simmel os trata como algo que precisa ser explicado. 
O segundo ponto tem a ver com a maneira como Simmel explica a emergência das coisas mais abstratas a partir das coisas mais concretas. Ele examina fenômenos em e por meio de relações e assim desenvolve um modo relacional de pensar. Sua obra insere as relações no centro da sociologia. Cada unidade é composta de relações.

Em terceiro lugar, a obra de Simmel exerceu também uma grande influência sobre como percebemos o mundo hoje. Ele dedica sua atenção às agitações da vida moderna cotidiana, coisa que, nos outros clássicos, não é objeto de muita reflexão. Para ele, a vida moderna se manifesta na forma de relacionamentos transitórios e numa velocidade crescente da vida. Ele pertence claramente à tradição do modernismo, iniciada por Baudelaire, para o qual a modernidade era "o transitório, o passageiro, o contingente". Simmel transformou o transitório, o passageiro e o contingente em um objeto da sociologia.

Creio que o que herdamos de Simmel é, sobretudo, um determinado modo de pensar que ainda possui um grande potencial de enriquecer o nosso pensamento, mas que, em alguns aspectos, não se encaixa muito bem na grande tradição sociológica. Por causa disso, ele representa um desafio para nós. E talvez pudéssemos dizer que a palavra "desafio" possui até um terceiro sentido, relacionado a como aceitamos a dádiva de seu pensamento, por assim dizer. Quando a aceitamos, aceitamos concomitantemente um desafio. E há uma obrigação tácita de fazer algo com as ideias e com os conceitos que recebemos. Caso contrário, há o perigo de interrompermos a corrente de reciprocidade.

L.W. Quais são os aspectos mais insuficientes ou as limitações do pensamento de Simmel para nós hoje? Ou: O que envelheceu e morreu?

O.P. As visões de Simmel em relação às mulheres e sua prática de ver as mulheres como mais próximas da natureza do que os homens, considerados mais culturais, certamente pertencem a esta categoria. Outra coisa é sua visão romântica e idealizada do gênio excepcional e da individualidade heróica de pessoas como Goethe, Michelangelo, Rembrandt e Rodin, por exemplo. Seu modo de ver a produção de arte em termos individualistas parece antiquado à luz de contribuições mais recentes de autores como Howard Becker, que trata a arte como empreendimento coletivo, como um produto da cooperação entre pessoas. A visão romântica da individualidade certamente não sobreviveu ao teste do tempo, e é bom termos deixado isto para trás. Além de ver a individualidade como valor positivo, sua obra inclui também outros valores tomados como dados, como a relação entre meios e fins. Ao prezar certos valores e ao se preocupar com certas tendências, a obra de Simmel ocasionalmente parece bastante conservadora quando avaliada do ponto de vista contemporâneo. 
Além disto, creio também que, embora Simmel cultive um modo relacional de pensar, sua maneira de pensar por vezes não é capaz de ir ao ponto, na medida em que frequentemente opera numa base dialética. A meu ver, a dialética é uma ferramenta por demais grosseira para explicar e conferir sentido ao nosso mundo complexo e interligado em redes. As redes ou os agrupamentos em que estamos emaranhados e que nos constituem não são estruturados em pares opostos. Na maioria das vezes, elas conectam coisas irregulares, indefinidas e incomensuráveis e coisas que existem em escalas diferentes. Seria simplista demais analisar a constituição de qualquer rede na base de tese e antítese. O mundo é muito mais rico e complexo do que isso. Simmel tenta abstrair a complexidade do mundo em formas puras e dualismos e dicotomias básicas, e, neste sentido, precisamos de abstrações melhores do que aquelas que ele nos oferece para entendermos a confusão da realidade em que vivemos. O fato de que, em última análise, Simmel modele a sociação segundo a relação diádica entre eu e você é sintomático. A fim de realmente expandir o potencial da sociologia da sociação de Simmel para o pensamento relacional, creio que o modelo diádico precisa ser abandonado e substituído por um modelo mais complexo. Cada díade já é condicionada por um terceiro, talvez por múltiplos terceiros, sejam eles incluídos ou excluídos.

A última coisa que eu gostaria de mencionar é o papel constitutivo dos objetos e fluxos materiais em nossas relações, algo pelo qual me interesso muito em meu próprio trabalho, especialmente nos últimos cinco anos. Precisamos reconhecer que o que faz de Simmel um autor sociológico e filosófico excepcional é sua atenção a objetos concretos como a asa de um jarro, a moldura de um retrato, a ruína, o dinheiro, a ponte e a porta. No entanto, ele não foi suficientemente preciso quando falou de como as coisas e os materiais são mobilizados e participam da constituição do nosso convívio. Estudiosos mais recentes demonstraram uma sensibilidade maior ao compartilhamento específico e ativo das coisas e da matéria em nossas coletividades. As pessoas não vivem apenas entre si, mas intimamente entrelaçadas com as coisas e os fluxos materiais. Isso nos obriga a refletir de modo diferente sobre o que constitui a subjetividade humana, ou seja, sobre o que significa ser humano.

L.W. Seu novo livro sobre The gift and its paradoxes parece ser muito interessante e um pouco provocativo. Reproduzo aqui duas de suas perguntas mais importantes: "o que é o dado no ato de dar?" e "em que consiste dar uma dádiva?" Você poderia falar um pouco sobre isso?

O.P. Certamente. Com este livro, eu quis desafiar a concepção, amplamente difundida e basicamente inquestionada na literatura sociológica e antropológica, da dádiva como uma forma de troca. Contrariando esta visão, meu livro examina a dádiva em termos do ato de dar. Ao fazê-lo, vim a desafiar 
também um dos pressupostos básicos de meu próprio pensamento. Tendo até então acatado a ideia de Simmel de que cada relação se baseia em reciprocidade ou troca como algo mais ou menos dado, perguntei-me e tentei perceber se a troca não derivava, de fato, de uma relação mais básica, de um dar unilateral e irreversível.

No que diz respeito à perspectiva de troca, poderíamos citar aqui dezenas de autores "culpados", por assim dizer, de reduzir a dádiva à troca, mas agora quero citar apenas um, talvez o mais influente: Marcel Mauss. Em seu escrito clássico "Essai sur le don", Mauss insiste que não há presentes voluntários e gratuitos, mas que presentes são sempre marcados por três obrigações: a obrigação de dar, a obrigação de receber e a obrigação de reciprocar. Na opinião de Mauss, estas obrigações sempre configuram a dádiva como uma forma de troca. Segundo ele, cada presente se baseia no princípio do ut des, "Eu dou para que você dê". Desde então, vários outros têm observado a norma da reciprocidade que subjaz ao presente. É claro que, em certo sentido, é perfeitamente legítimo tratar a dádiva sob a perspectiva da troca. É verdade que a maioria dos presentes precisa ser paga. Dívidas precisam ser quitadas e as balanças precisam ser equilibradas. No entanto, nem todo presente é uma forma de troca. A perspectiva de troca ignora várias formas e ocasiões de dádiva que não podem ser reduzidas à troca, como as doações caridosas, o cuidado dos pais, a doação de sangue e o autossacrifício, por exemplo. Além disto, a meu ver, a perspectiva de troca suscita outros três problemas.

O primeiro é que, curiosa e paradoxalmente, embora a maioria dos estudos sobre a dádiva insista no fato de que as relações de dádiva operem segundo um princípio completamente diferente daquele que rege o mercado, na medida em que esses estudos tratam da dádiva como forma de troca seu modo de falar disto é construído com o linguajar do mercado. David Graber fala sobre isto em seu livro Debt: the first 5,000 years.

Em segundo lugar, como estes estudos consideram como "dado" que a dádiva é recíproca, estas perspectivas que enfatizam a troca permanecem mais ou menos cegas a qualquer brecha, incompatibilidade ou ruptura possível entre a dádiva e a reciprocidade; por isto a diferença entre presente e empréstimo ou dívida se torna, às vezes, quase que inexistente nestas perspectivas. Confundir a dádiva com a troca solapa de forma significativa o ato de dar envolvido na dádiva. E, em princípio, presentes são dados, não trocados (em várias línguas existe também um vínculo semântico estreito entre "dar" e "dádiva"). O princípio do ato de dar é distinto daquele da troca. Em um sentido estrito, se sempre damos alguma coisa apenas "em troca de", nada está efetivamente sendo "dado". Se há uma garantia de que aquilo que é dado será compensado, já não estamos mais lidando com a dádiva, mas com um relacionamento contratual, por exemplo. No livro, sugiro que a dádiva pura, a fim de ser possível, exige perda e gastos, sendo dada com abandono. $\mathrm{Na}$ 
ausência do abandono, a dádiva nega-se a si mesma, pois neste caso nada é realmente dado. No caso de uma dádiva pura e absoluta, é possível a ausência de retorno. Ela precisa interromper o ciclo da troca, não se subordinando a ele. $O$ ato de dar não pode retornar para si mesmo; precisa haver algo perdido no ato da doação e na coisa dada, algo que não retorna para o sujeito que dá. Neste sentido, a dádiva precisa "perecer" para o doador.

O terceiro problema da redução da dádiva à troca é que ela não leva a sério o fato de que pessoas possam querer dar por generosidade autêntica. É exatamente isto que Bourdieu critica nas análises "objetivistas" - como a de Lévi-Strauss. Segundo Bourdieu, a dádiva realmente pretende ser gratuita, tanto na experiência individual como no julgamento público. No entanto, ao mesmo tempo em que insiste em dar atenção a como os sujeitos interpretam e experimentam a dádiva, o próprio Bourdieu concede às visões dos agentes muito menos peso, fazendo preponderar o olhar supostamente "objetivo" do sociólogo observador. Ele leva a experiência dos sujeitos a sério apenas no sentido em que acredita que se trata necessariamente de obscurecer a natureza "verdadeira" da dádiva. Assim, a visão dos agentes da dádiva vista como doação é, para Bourdieu, nada mais do que uma concepção errada - embora às vezes consciente e deliberada - da verdade objetiva da dádiva como forma de troca. Ele nunca leva em consideração a possibilidade de os agentes estarem corretos com relação a seu entendimento da verdadeira natureza do presente.

Os dois primeiros problemas são conceituais; o terceiro é mais do tipo empírico e metodológico.

Contudo, mesmo que a perspectiva que enfatiza a visão da dádiva como troca não possa ser aceita como verdade última e inquestionada sobre a dádiva, em The gift and its paradoxes sugiro também que a doação empírica nunca pode ser separada completamente da troca. É provável que muitos eventos de doação ocorram num sistema de reciprocidade já estabelecido e de longo alcance, e assim o ato de dar já é uma contra-dádiva; ou então que a reciprocidade seja meramente adiada, estendendo-se tão longe no tempo a ponto de se tornar menos evidente. Assim, se contemplarmos a dádiva exclusivamente em termos de um ato isolado de doação, dissociado do que a precede e sucede, corremos o risco de não reconhecer as redes de reciprocidade dentro das quais ela ocorre e para as quais ela pode contribuir.

Assim, argumento no livro que, na realidade, não existe a dádiva pura. Trata-se mais de um valor conceitual limite do que um fato realizável. Derrida argumenta que, no limite máximo, a dádiva não pode estar presente como dádiva, nem para o doador, nem para aquele que a recebe. Pois quando está, no exato momento em que a dádiva é percebida e aceita, ela se anula como dádiva, porque sua própria identificação como dádiva logo a leva de volta à economia da troca: aquele que recebe não pode impedir de sentir a obrigação 
de, no mínimo, recompensar com gratidão, e o doador faz um pagamento simbólico a si mesmo, por exemplo, louvando ou parabenizando a si mesmo pelo bom ato. Assim, a troca não só nega à dádiva a sua essência, como a própria intenção de dar gratuitamente já basta para fazê-lo. Para Derrida, a dádiva vista empiricamente - é impossível, pois ela nunca poderia ocorrer e se apresentar como dádiva. É a própria figura do impossível, anunciando a si mesmo e entregando a si mesmo ao pensamento como o impossível [Given time: I. Conterfeit money, Chicago: Chicago University Press, i994, p. 7].

Ao mesmo tempo, é importante observar que a dádiva-troca é condicionada por sua dependência do incondicional. Ela deve ao menos orientar-se pelo ideal da dádiva pura e absoluta, mesmo que este jamais possa se realizar. Se eu desse aos outros apenas na mesma medida em que eles me dão, o ato de dar se anularia a si mesmo, pois neste caso eu não estaria dando e desistindo de nada. A dádiva seria como uma dívida quitada. É interessante que, assim, o ato de dar e a troca pareceriam se incorporar um ao outro no momento exato em que eles se excluiriam. Por isto, ao mesmo tempo em que eu insisto numa distinção conceitual entre a doação e a troca, eu também considero importante reconhecer que, em todo o seu antagonismo, elas abarcam duas dimensões irredutíveis de cada dádiva.

Além de usar o ato de dar como meu tema principal, exploro no livro também o que é dado no ato de dar, isto é, o doado. Na sociologia da dádiva, a visão de que esta nada mais é do que uma relação é praticamente considerada um truísmo. Eu, porém, quis recuar um passo e perguntar o que é a dádiva: trata-se de uma coisa ou de uma relação? Ou, em termos mais exatos, parecia-me que a dádiva torna visível como uma relação se transforma em uma coisa; e uma coisa, em uma relação. Isto é algo que Mauss também enfatiza. Na troca-dádiva, a seu ver, as coisas se misturam com pessoas. As tribos não ocidentais estudadas pelo antropólogo Mauss recorrem a associações de forma e conhecem as obrigações e a honra por meio da circulação de objetos, tais como colares e pulseiras, entre seus membros. Em relação a discussões e debates mais recentes sobre materialidade e objetos, é interessante observar que Mauss não trata os objetos como coisas passivas e inertes, mas como animadas e com poder inerente. A compreensão de Mauss, porém, da vitalidade própria dos objetos ou coisas é falha por causa de seu animismo. Para Mauss, então, as coisas podem ser ativas não em virtude de seus materiais e de suas características materiais, mas por causa de um espírito que lhes é atribuído. Abordagens mais recentes das forças generativas das coisas têm prestado atenção em como as coisas são ativas ou tornam-se ativas por meio da matéria, ou seja, em virtude de suas características materiais.

L. W. Você poderia falar um pouco sobre sua pesquisa atual sobre o lixo? Ela tem também um lado empírico? 
O. P. Sim, tem. De certa forma, eu tenho feito as coisas em ordem inversa (apesar de nunca ter tido a intenção de fazê-lo deliberadamente): os sociólogos tendem a escrever suas sínteses teóricas apenas em idade avançada, após realizarem todo o seu trabalho empírico ao longo de suas carreiras... Eu, porém, escrevi primeiro alguns livros teóricos e apenas agora estou começando a realmente também fazer algum trabalho empírico. No entanto, posso garantir-lhe que não penso em abandonar o trabalho teórico em momento algum. Na verdade, antes de terminar o livro sobre o legado de Simmel, devo completar outro livro um tanto provocativo, intitulado Manifesto for a new sociological imagination, no qual tento devolver a imaginação à imaginação sociológica, para expressar-me de forma um pouco irônica. Em termos gerais, e agora volto a falar em tom mais sério, não considero a divisão entre trabalho empírico e trabalho teórico algo particularmente sustentável. Em alguns aspectos, o trabalho empírico é, para mim, apenas uma maneira de abordar e chegar a problemas teóricos, até mesmo problemas ontológicos. E repito: imagino o trabalho teórico como uma maneira de produzir, como um artesanato; nele também trabalhamos com alguns materiais. A teoria se torna inútil se ela não preservar qualquer conexão com aquilo que está acontecendo no mundo ao nosso redor. Em meu livro sobre a dádiva, levo o envolvimento com materiais para além do ponto que tenho alcançado em meu trabalho teórico até agora: no livro, aplico filosofia e teoria social a filmes, romances, contos de fada etc. Eu realmente acredito que, às vezes, a ficção pode enriquecer e intensificar conceitos. Mas isto já é o suficiente.

Voltando ao ponto: o projeto sobre o lixo que estou iniciando com meus colegas é, de fato, um projeto empírico. Na verdade, acreditamos que, visto que grande parte dos estudos existentes sobre o lixo é predominantemente teórico, uma das qualidades do nosso projeto é justamente seu envolvimento profundo e minucioso com o lixo. Fazemos trabalho de campo nas casas das pessoas, em aterros, em salas de controle e em diferentes tipos de esgoto, por exemplo. Neste projeto, nos interessamos pelo papel do lixo na sociedade, pelo consumo e pelo estilo de vida contemporâneo em diferentes níveis. Partimos da pressuposição de que o lixo e a administração do lixo são essenciais para a constituição de sociedade: não existe sociedade sem eles. E examinamos isto por meio de vários estudos de casos empíricos. No estudo de caso que eu mesmo estou realizando com meu amigo e colega Turo-Kimmo Lehtonen, nos concentramos na cultura dos catadores de lixo. O que nos interessa nesta prática de remexer o lixo são questões de valor e propriedade e também as razões políticas e ideológicas para o estilo de vida de muitos catadores de lixo. Acima de tudo, porém, achamos fascinante esta prática de catar lixo, porque ela nos fornece um ponto de vista vantajoso para compreender o modo de vida contemporâneo e o papel do consumo no capitalismo. Os catadores de lixo que entrevistei me disseram que os contêineres de 
lixo dos grandes supermercados transbordam literalmente de comida perfeitamente comestível, muitas vezes em quantidade muito maior do que eles conseguem levar. Assim, as lixeiras acabam sendo verdadeiras cornucópias. E o fato de que as pessoas no rico Hemisfério Norte podem se dar ao luxo de jogar fora essas quantidades de comida comestível é, para mim, um bom indicador de abundância. Isto significaria que, ao contrário do que costumamos acreditar, não vivemos num mundo de escassez, mas num mundo de abundância. Não temos pouco demais, mas demais: as montanhas crescentes de lixo são prova disso. O lixo é justamente este "demais"; é excesso. Temos comida para I2 bilhões de pessoas. O único problema é que ela é distribuída com desigualdade, assim como o lixo também. Na verdade, a distribuição global do lixo parece ser inversamente proporcional à riqueza: os ricos, aqueles que mais têm, jogam seu lixo aos pobres, àqueles que têm muito pouco ou nada. Assim, o estudo do lixo nos permite abordar também temas como a desigualdade e os fluxos materiais globais.

Entrevista concedida em novembro e dezembro de 2014 |

Aprovada em Io/oI/20I5

Leopoldo Waizbort é professor do Departamento de Sociologia da Universidade de São Paulo (USP) e pesquisador do Conselho Nacional de Desenvolvimento Científico e Tecnológico (CNPq). É autor de As aventuras de Georg Simmel (2000). 
SIMMEL HOJE:

ENTREVISTA COM OLLI PYYHTINEN

Resumo

Nesta entrevista, o jovem sociólogo finlândes Olli Pyyhtinen, autor de um importante e recente livro sobre Georg Simmel (Simmel and "the social"), explica o que julga central na sociologia e no pensamento de Simmel, assim como alguns de seus limites e desafios para a sociologia contemporânea. Destaca-se aqui o relacionismo radical de Simmel. Discute a questão da dádiva, tal como pensada por Mauss e outros, e a dinâmica que a estabelece e, ao mesmo tempo, a anula. Por fim, indica alguns elementos de sua pesquisa corrente sobre o lixo como índice de abundância e de sua relação com a distribuição da riqueza no mundo.

SIMMEL TODAY: AN INTERVIEW WITH OLLI PYYHTINEN

Abstract

In this interview, the young Finn sociologist Olli Pyyhtinen, author of an important and recent book on Georg Simmel (Simmel and "the social"), explains what he believes to be central in Simmel's sociology and thinking, as well as some of its limitations and challenges for conPalavras-chave Simmel; Relação;

Dádiva;

Sociologia;

Antropologia. temporary sociology. His perspective highlights Simmel's radical relationism. He also discusses the problem of the gift, as proposed by Mauss and others, and the dynamics that at the same time establishes and denies it. Finally, he indicates some elements of his current research on garbage as an index of abundance in contemporary society and its relation to the distribution of wealth in the world.

Keywords

Simmel;

Relationship;

Gift;

Sociology;

Anthropology. 